\title{
PEMANFAATAN SEL SURYA 50 Wp PADA LAMPU PENERANGAN RUMAH TANGGA DI DAERAH HINTERLAND
}

\author{
Reza Nandika ${ }^{1}$, Pamor Gunoto ${ }^{2}$ \\ ${ }^{1,2}$ Teknik Elektro Universitas Riau Kepulauan \\ Jurusan Teknik Elektro Fakultas Teknik Universitas Riau Kepulauan \\ Jln. Batu Aji Baru No.99, Kepulauan Riau Telepon: ( 0778 ) 392752 \\ rezanandikameng@gmail.com ${ }^{2}$
}

Abstrak

\begin{abstract}
Kebutuhan energi listrik semakin berkembang dan tidak dapat dipisahkan dari kebutuhan masyarakat. Semakin berkurangnya sumber energi fosil yang merupakan tulang punggung penghasil energi listrik menyebabkan pemikiran pentingnya untuk penyediaan sumber energi listrik terbarukan. Penerapan PLTS sebagai sumber energi listrik alternatif di daerah hinterland sangatlah tepat mengingat potensi energi surya rata-rata cukup baik. Indonesia merupakan daerah ekuator yang menyebabkan ketersediaan sinar matahari hampir sepanjang tahun. Indonesia memiliki potensi listrik surya $4,5 \mathrm{kw} / \mathrm{m}^{2}$ yang dapat dimanfaatkan secara cuma-cuma. Penelitian ini mencoba untuk memanfaatkan panel sel surya 50 Wp untuk penerangan rumah tangga dengan beban lampu LED bagi rumah tangga masyarakat yang tinggal di daerah hinterland. Pengukuran besarnya daya akan dilakukan disetiap jam sepanjang hari dimulai dari mulai pukul 06.00 sampai 18.00 diperoleh keluaran daya rata-rata sebesar 38,9 Watt. Adapun pemakaian beban dengan lampu LED sebesar 36 watt selama 12,75 jam dengan efisiensi penggunaan biaya beban sebesar Rp. 142.000 per bulan.
\end{abstract}

Kata kunci : Sumber energi terbarukan, Panel sel surya $50 \mathrm{Wp}$, PLTS, Daerah hinterland

\section{Pendahuluan}

\subsection{Latar Belakang}

Suatu kenyataan bahwa kebutuhan energi listrik semakin berkembang dan tidak dapat dipisahkan dari kebutuhan hidup masyarakat, selain itu semakin berkurangnya sumber energi fosil yang saat ini masih merupakan tulang punggung dan komponen utama penghasil energi listrik di Indonesia, hal ini menyebabkan pemikiran untuk penyediaan sumber energi listrik terbarukan (LIPI, 2017). Setiap tahunnya konsumsi energi listrik Indonesia terus meningkat sejalan dengan pertumbuhan ekonomi nasional. Peningkatkatn kebutuhan listrik diperkirakan dapat tumbuh ratarata $6,5 \%$ per tahun hingga tahun 2020.

Energi alternatif dan yang terbarukan mempunyai peran yang sangat penting dalam memenuhi kebutuhan energi. Hal ini disebabkan penggunaan bahan bakar untuk pembangkit-pembangkit listrik konvensional dalam jangka waktu yang panjang akan mengurangi sumber minyak bumi, gas dan batu bara secara cepat. Sehingga akan membuat semakin menipisnya cadangan minyak dan yang tidak kalah pentingnya adalah bahaya polusi yang ditimbulkan dari penggunaan minyak tersebut. Salah satu upaya yang telah dikembangkan adalah Pembangkit Listrik Tenaga Surya (PLTS).

Konsumsi listrik Indonesia yang begitu besar akan menjadi suatu masalah bila penyediaaana tidak sejalan dengan kebutuhan. Kebijakankebijakan yang diambil Perusahaan Listrik Negara (PLN) sebagai BUMN (Badan Usaha Milik Negara) penyedia listrik semakin menunjukkan bahwa 
PLN sudah tidak mampu lagi memenuhi kebutuhan listrik Nasional. Oleh sebab itu terjadi tidak meratanya penyediaan energi listrik terutama bagi masyarakat yang berada di daerah hinterland. Selain permasalahan dana untuk memperluas pembangunan jaringan listrik, kondisi geografis Indonesia yang kepulauan dan bergunung-gunung serta pola pemukiman yang menyebar, menimbulkan permasalahan tersendiri dalam pendistribusian tenaga listrik. Kebutuhan dasar masyarakat hinterland akan energi listrik adalah terutama digunakan sebagai penerangan rumah.

Wilayah Indonesia terletak di daerah ekuator yaitu wilayah yang membagi bola bumi menjadi bagian utara dan selatan. Posisi ini menyebabkan ketersediaan sinar matahari hampir sepanjang tahun. Berdasarkan peta isolasi matahari, wilayah Indonesia memiliki potensi energi listrik surya sebesar $4,5 \mathrm{~kW} / \mathrm{m}^{2}$ (Kumara, 2010). Panel surya dibutuhkan sebagai media pemanfaatan panas energi surya menjadi energi listrik. Gambar 1 memperlihatkan pemanfaatan panel surya sebagai penghasil energi listrik.

Pembangkit Listrik Tenagan Surya (PLTS) memiliki beberapa keuntungan. Pertama pembangkit listrik tenaga surya tidak akan pernah habis. Keuntungan kedua pembangkit listrik tenaga surya tidak menghasilkan emisi

karbon sehingga ramah lingkungan. Keungtungan ketiga, PLTS hanya membutuhkan sedikit perawatan (berenergi.com, 2017)

\subsection{Rumusan masalah}

Dengan berkurangnya pasokan energi listrik dari PLN, maka perlu dilakukan upaya dalam mengurangi pemakaian beban listrik di rumah tangga yang berasal dari PLN. Pemanfaatan energi listrik alternatif sebagai sarana untuk digunakan sebagai sumber listrik bagi masyarakat hinterland pengganti energi listrik yang berasal dari generator.. Berdasarkan uraian diatas, maka pertanyaan penelitian ini dapat dirumuskan sebagai berikut :

1. Bagaimana merancang sistem pembangkit listrik tenaga surya yang dapat digunakan untuk rumah tangga di daerah hinterland ?

2. Bagaimana menentukan dan menyesuaikan daya listrik yang dipakai untuk beban listrik lampu penerangan di rumah tangga?

\subsection{Tujuan Penelitian}

Dari masalah yang ada tersebut diatas, maka tujuan dari penelitian ini adalah :

1. Untuk merancang sistem sumber energi listrik tenaga surya sebagai energi alternatif pengganti genset pada skala rumah tangga di daerah hinterland.

2. Perhitungan penghematan biaya yang diperoleh dari sistem sumber energi listrik tenaga surya dengan beban lampu penerangan di rumah tangga diabndingkan dengan genset

\section{Tinjauan Pustaka}

\subsection{Penelitian Terdahulu}

1. Penelitian yang dilakukan Jatmiko, dkk (2011). Judul penelitian Pemanfaatan Sel Surya Dan Lampu Led Untuk Perumahan. LED digunakan sebagai beban, panel surya dihubungkan secara parallel yang dapat menghasilkan keluaran 
sebesar 20 watt, panel surya dihubungkan ke BCR (Battery Charge Regulator) BCR berfungsi sebagai pengatur pengisian accu jika tegangan accu sudah tidak mampu lagi menyuplai beban maka secara otomatis akan berpindah ke jala-jala listrik PLN. Inverter berfungsi untuk mengubah tegangan DC dari accu ke AC. Pengujian dilakukan pada malam hari, pengisian battery dilakukan di awal terbit hingga terbenam matahari. Dengan menggunakan sel surya $20 \mathrm{Wp}$ ada saat keadaan cerah sel surya mampu mensuplai beban selama 11,5 jam.

2. Penelitian selanjutnya oleh Abdur Rozak, (2014) yang berjudul Pemanfaatan Sel Surya Untuk Konsumen Rumah Tangga Dengan Beban Dc Secara Paralel Terhadap Listrik Pln. Melakukan pengukuran energy harian sebelum menggunakan sel surya dan melakukan pengukuran energy harian dengan menggunakan sel surya. Sel surya yang digunakan dihubungkan secara parallel agar dapat menghasilkan arus yang besar. Sel surya diletakkan dengan ketinggian 5 meter diatas permukaan tanah. Kontroler digunakan sebagai pengontrol pengisian baterai dan juga untuk menghindari mengalirnya arus dari baterai ke panel surja jika panel surya tidak bekerja. Apabila baterai terisi penuh oleh panel surya maka kontroler akan memutus pengisian. Hasil penelitian menyatakan bahwa penghematan adalah 18,48\%. Penghematan 0,51 kwh perhari atau Rp. 511,77

3. Dafi Dzulfikar, Wisnu Broto, (2016) optimalisasi pemanfaatan energi listrik tenaga surya skala rumah tangga dengan penggabungan antara energi surya dan listrik dari PLN

4. Ari Rahayuningtyas, Seri Intan Kuala, Ign. Fajar Apriyanto, (2014) studi perencanaan sistem Pembangkit Listrik Tenaga Surya (PLTS) dengan Solar Home System (SHS) yang menggunakan panel surya $50 \mathrm{Wp}$ sebagai penyedia energi alternatif untuk mendukung program ramah lingkungan dan energi terbarukan.

5. Anwar Ilmar Ramadhan, Ery Diniardi, Sony Hari Mukti, (2016), menganalisa desain PLTS dengan kapasitas $50 \mathrm{Wp}$ secara skala laboratorium dengan membandingkan pemancaran secara optimun di berbagai posisi panel surya dan tegangan atau arus yang dihasilkan.

\subsection{Listrik Pedesaan}

Pembangunan listrik edesaan merupakan penugasan pemerintah untuk memberikan listrik kepada masyarakat pedesaan. Kebijakan yang diambil oleh Direktorat Jendral Ketenagalistrikan (DJK) dan PLN dalam pembangunan listrik desa adalah untuk memenuhi rasio elektrifikasi $80 \%$ dan desa berlistrik 98,9\% di tahun 2014. Pembangunan ini sesuai dengan RPJM Departemen ESDM 2010-2014, yaitu melistriki desa baru maupun lama yang sebagian dari dusun tersebut belum belistrik, daerah terpencil dan daerah perbatasan, serta dimungkinkan untuk pengadaan hybrid PLTS dan hybrid PLTB yang sistemnya terhubung dengan grid PLN. Secara umum tujuan dari pelistrikan daerah edesaan, merupakan usaha dalam memberikan listrik kepada desa-desa, terutama untuk negara berkembang. Meliputi : 
1. Penggunaan listrik untuk tujuan produktif (ekonomi)

Fokus pelistrikan desa pada umumnya diletakan pada usahausaha untuk membangkitkan atau meningkatkan kegiatan-kegiatan produktif masyarakat. Penggunaan listrik bisa untuk melakukan kegiatan seperti pompa irigasi, industri pedesaan, bengkel kecil, eralatan pertanian, fasilitas pendingin untuk ikan dll.

2. Manfaat sosial

Program misi sosial dimaksudkan untuk membantu kelompok masyarakat tidak mampu, menjaga kelangsungan dalam upaya perluasan akses pelayanan listrik pada wilayah yang belum terjangkau listrik, dan mendorong pembangunan dan pertumbuhan ekonomi serta meningkatkan kesejahteraan rakyat pedesaan.

\subsection{Sel Surya}

Panel sel surya adalah sebagai komponen yang merubah energi cahaya matahari menjadi energi listrik. Panel surya terbuat dari bahan semikonduktor (umumnya silicon) yang apabila disinari oleh cahaya matahari dapat menghasilkan arus listrik. Prinsip kerja dari panel surya adalah jika cahaya matahari mengenai panel surya, maka elektron-elektron yang ada pada sel surya akan bergerak dari $\mathrm{N}$ ke $\mathrm{P}$, sehingga pada terminal keluaran dari panel surya akan menghasilkan energi listrik. Besarnya energi listrik yang dihasilkan oleh panel surya berbeda-beda tergantung dari jumlah sel surya yang dikombinasikan didalam panel surya tersebut. Keluaran dari panel surya ini adalah berupa listrik arus searah (DC) yang besar tegangan keluarannya tergantung jumlah sel surya yang dipasang didalam panel surya dan banyaknya sinar matahari yang menyinari panel surya tersebut (Bansai, 1990).

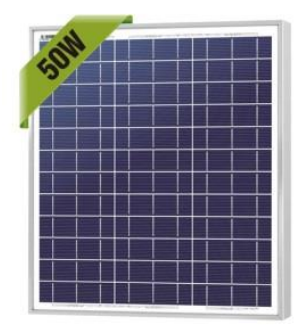

Gambar 2. Modul sel surya 50

$\mathrm{Wp}$

Sel Surya yang beredar di pasaran sudah dikemas dalam bentuk modul. Oleh karena itu modul sering disebut sebagai modul sel surya. Modul ini tersusun dari beberapa sel surya yang masing-masing dihubungkan secara seri untuk memperoleh tegangan listrik nominal yang dibutuhkan. Untuk modul sel surya kapasitas daya $50 \mathrm{Wp}$ tersusun dari 32 sel yang terhubung seri seperti pada gambar 2 diatas.

Masing-masing sel mempunyai daya keluaran listrik sektar 1,6 watt, dengan arus dan tegangan nominal sekitar 3 ampere dan 0,53 volt. Oleh karena itu, model sel surya $50 \mathrm{Wp}$ mempunyai keluaran arus nominal 3 ampere dan tegangan nomimal 16,9 volt.

Pembangkit Listrik Tenaga Surya (PLTS) di Indonesia yang biasanya digunakan untuk daerah pedesaaan dengan menggunakan sebuah sistem yang disebut Solar Home System (SHS) yang umumnya menggunakan modul sel surya $50 \mathrm{Wp}$ - $100 \mathrm{Wp}$ (Watt peak) dan menghasilkan listrik harian sebesar 150-300 Wh (Dafi Dzulfikar, 2016). Pengertian $50 \mathrm{Wp}$ adalah sel surya tersebut memiliki 50 Watt peak pada saat terik matahari. Dapat diasumsikan 
peak per hari adalah 4 -5 jam sehingga diperoleh 200 Watt hour per hari yang merupakan kapasitas pemakaian maksimal dalam satu hari.

\subsection{Kontroler (Solar Charge Controller)}

Solar charge controller adalah rangkaian elektronik yang mengatur proses pengisian baterai. Proses mengatur pengisian arus listrik dari panel surya ke baterai dan sebaliknya. Saat ini baterai tersisa $20 \%$ sampai $30 \%$, maka regulator akan memutuskan dengan beban. Regulator baterai juga mengatur kelebihan mengisi baterai dan kelebihan tegangan panel surya. Manfaat dari alat ini juga untuk menghindari full discharge dan overloading serta memonitor suhu baterai. Kelebihan tegangan dan pengisian dapat mengurangi umur baterai.

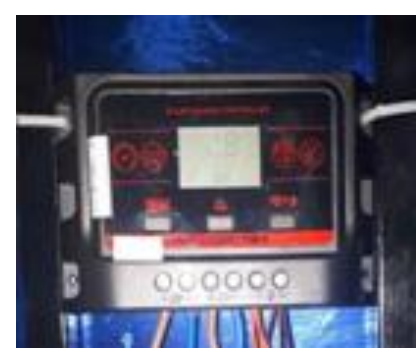

\section{Gambar 3. Solar charge controller}

Alat pengontrol ini juga mencegah pengaliran arus dari baterai ke panel surya ketika proses pengisian sedang tidak berlangsung. Apabila baterai sudah terisi penuh, maka aliran DC dari panel surya akan diputuskan agar baterai tidak lagi menjalalni pengisian. Gambar 3 merupakan gambar solar charge controller.

Untuk penggunaan sel surya yang mempunyai tegangan 12 volt, maka menggunakan solar charge controller dengan tegangan 12 volt, sedangkan kapasitas arus listriknya disesuaikan arus hubung-singkat (short circuit current, $\mathrm{I}_{\mathrm{sc}}$ ) dari modul sel surya yang digunakan ditambah $10 \%$ dari nilai $\mathrm{I}_{\mathrm{sc}}$. Pada modulsel surya $50 \mathrm{Wp}$, nilai $\mathrm{I}_{\mathrm{sc}}$ sekitar 3,25 A, oleh karena itu arus minimal solar charge controller yang digunakan sekitar 3,6 A.

\subsection{Baetari (Aki)}

Baterai atau Aki dibutuhkan sebagai penyimpanan dari listrik yang dihasilkan panel surya oleh karena itu baterai adalah penyimpan energi listri pada saat energi matahari tidak ada. Kapasitas baterai yang digunakan tergantung dari besarnya beban yang digunakan dan lamanya penyimpanan energi listrik.

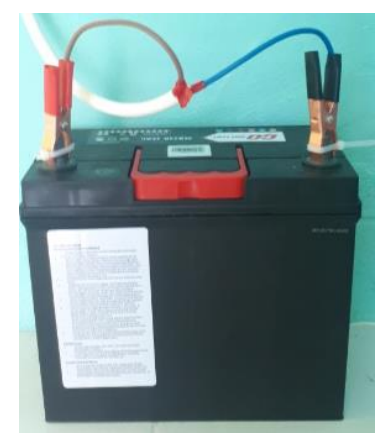

Gambar 4. Aki kapasitas 45 Ah/12 V Hubungan baterai dengan beban adalah dihubungkan secara langsung paralel. Jika baterai telah terisi penuh maka secara otomatis proses pengisian akan terhenti. Penggunaan baterai disesuaikan dengan tegangan beban yang dipakai. Gambar 4 adalah baterai yang digunakan dengan spesifikasi tegangan 12 volt dan arus $45 \mathrm{Ah}$.

\subsection{Solar Home System (SHS)}


Sistem PLTS yang cukup besar penerapannya di Indonesia adalah sistem penerangan rumah secara individual yaitu Solar Home System (SHS). Umumnya SHS berupa sistem berskala kecil, dengan menggunakan panel surya 50-100 Wp (Watt peak) dan menghasilkan listrik harian sebesar 150-300 Wh. Jumlah daya sebesar itu diharapkan dapat memenuhi kebutuhan penerangan rumah. Karena skalanya kecil maka memakai sistem DC, agar tidak terkena loses dan self consumption akibat penggunaan inverter. SHS merupakan sistem penerangan rumah menggunakan sel surya, yang diterapkan untuk daerah terpencil. Energi listrik yang dihasilkan oleh modul sel surya pada siang hari disimpan didalam aki untuk dimanfaatkan pada malam harinya. Aki yang digunakan adalah aki dengan tipe shallow disharge ( aki mobil) yang mudah diperoleh dipasaran. Aki jenis ini mempunyai DOD $25 \%$ (depth of discharge) yang berarti kapasitas daya listrik yang diperbolehkan untuk dimanfaatkan sebesar $25 \%$. Untuk menjaga agar aki tetappada kondisi baik pada saat digunakan maka SHS dilengakapi dengan Solar charge controller.

SHS idealnya digunakan untuk listrik di pedesaan yang jarak rumah satu dengan lainnya saling berjauhan, dan keperluan listriknya relatif lebih kecil, yakni hanya untuk memenuhi penggunaan dasar rumah tanga yaitu lampu penerangan. Penerapan sistem SHS di pedesaan didasarkan atas kajian pertimbangan fakto-faktor berikut :

1. Pola pemukiman antara rumah di desa cukup menyebar

2. Sulit untuk mendapatkan transportasi darat atau laut
3. Belum memerlukan integrasi dngan pembangkit lain

4. Modular, dan mudah dikembangkan

5. Kapasitas kecil sehingga mudah untuk di instalasi

6. Harga terjangkau

7. Radiasi matahari sebagai sumber energi mencukupi

8. Tidak tergantung terhadap BBM

\section{Metode Penelitian}

\subsection{Rancangan Penelitian}

Untuk metode penelitian dilakukan dengan beberapa tahap disesuaikan dengan proses perancanngan alat yang ada yaitu :

1. Penentuan panel surya yang akan digunakan yaitu sebesar $50 \mathrm{Wp}$, dimana disesuaikan dengan beban lampu penerangan yang digunakan

2. Penentuan kontroler (solar charge controller) yang akan digunakan, sehingga dalam aplikasinya tidak terjadi kesalahan penggunaan yang berakibat kurang baik atau dapat merusak panel surya maupun peralatan listrik yang ipasang nantinya

3. Baterai yang diperlukan sebagai penyimpan energi yaitu aki yang besarnya disesuaikan dengan beban yang akan dipakai

4. Jumlah beban lampu penerangan yang digunakan

Metodologi yang digunakan dalam desain Solar Home System ini dapat digambarkan dalam bentuk diagram alir (flowchart) seperti gambar 5 dibawah ini 


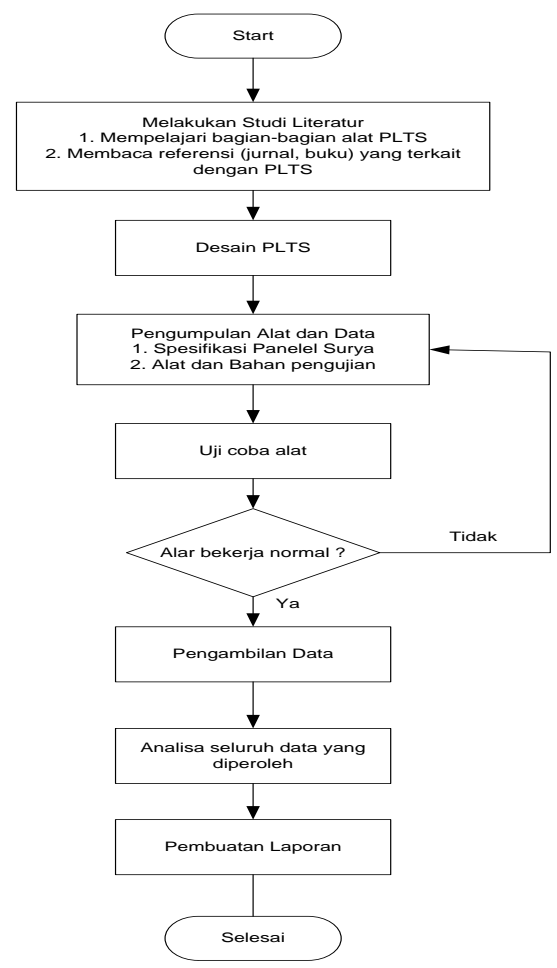

Gambar 5. Diagram Alir Penelitian

\subsection{Perancangan Alat}

Perancangan yang dilakukan dengan menggunakan panel sel surya $50 \mathrm{Wp}$ sebagai penghasil energi listrik dari energi matahari. Baterai dibutuhkan sebagai penyimpanan energi listrik yang dihasilkan dari panel sel surya. Pengontrol penyimpanan ke baterai diatur oleh sebuah kontroler, tujuan dari kontroler adalah sebagai penghubung serta pemutus pengisian energi listrik dari sel surya ke baterai. Keluaran dari sel surya berupa arus DC yang kemudian akan dialirkan ke beban lampu. Gambar 6 memperlihatkan blok perancangan sistem.

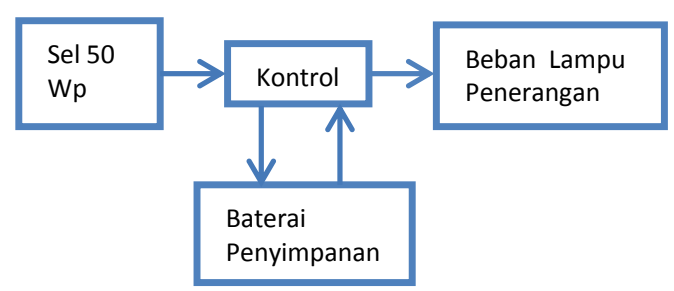

Gambar 6. Diagram blok sistem PLTS

Keterangan diagram blok :

a. Panel sel surya $50 \mathrm{Wp}$

Komponen utama dari PLTS yang dapat menghasilkan energi listrik DC. Panel surya terbuat dari bahan semikonduktor (silicon) yang apabila disinari oleh cahaya matahari dapat menghasilkan arus listrik.

b. Baterai/Aki

Baterai/Aki adalah sebagai penyimpan energi listrik yang dihasilkan oleh panel surya yang akan digunkan apabila sinar matahari tidak ada

c. Kontroler

Kontroler adalah alat yang digunakan mengatur pengisian arus dari panel surya ke baterai dan sebaliknya. Kontroler juga mengatur kelebihan mengisi tegangan ke baterai dan kelebihan tegangan dari panel surya

d. Beban Lampu

Beban lampu yang digunakan adalah berupa lampu bertegangan 12 volt DC dan mempunyai daya 12 watt sebanyak 3 biji.

Perancangan PLTS ini digunakan pada lampu penerangan sebesar 36 watt (3x12 watt) di rumah tangga selama 12 jam. Adapun intensitas radiasi matahari yang ditangkap oleh panel sel surya selama 12 jam mulai pukul 06.00 sampai 18.00.

Perancangan sistem PLTS ini dengan menentukan komponen-komponen yang dipakai yaitu :

1. Menentukan Beban pemakaian adalah 
Beban Pemakaian = Daya beban $\mathrm{x}$ lama pemakaian

$$
=(3 \times 12 \mathrm{~W}) \times 12 \mathrm{Jam}=432
$$
$\mathrm{Wh}$

2. Menentukan ukuran kapasitas panel sel surya yang sesuai dengan beban pemakaian

Kapasitas sel surya $=$ Total beban pemakaian harian / rata2 sinar matahari cerah

$=(36 \mathrm{~W} \times 12 \mathrm{Jam}) / 8 \mathrm{Jam}=54$ $\mathrm{Wp}$

3. Menentukan kapasitas baterai/aki adalah

Kapasitas baterai $=$ Total beban pemakaian harian / tegangan sistem $=(36 \mathrm{~W} \times 12 \mathrm{Jam}) / 12$ volt $=36$ $\mathrm{Ah}$

Pengujian dilakukan dengan mengukur berapa besar daya yang dihasilkan panel surya $50 \mathrm{Wp}$. Pengukuran dilakukan tiap jam mulai dari terbit matahari hingga terbenam matahari. Penghitungan konsumsi daya listrik sebelum menggunakan sel surya dan setelah menggunakan sel surya, ini bertujuan untuk memperoleh informasi berapakah penghematan yang dapat dilakukan dengan menggunakan pembangkit listrik tenaga surya untuk penerangan rumah tangga ini juga akan dilakukan.

Pada perancangan ini juga dilakukan perhitungan harga dari komponen-komponen PLTS seperti pada tabel 1 berikut :

Tabel 1. Daftar harga komponen PLTS

\begin{tabular}{|c|c|c|c|c|c|c|}
\hline & & & & B & S & \\
N & Jeni & & Har & a & at & \\
o & Bar & ek & Sat & y & u & Jumlah \\
& ang & & uan & a & n & \\
& & & & k & & \\
\hline
\end{tabular}

\begin{tabular}{|c|c|c|c|c|c|c|}
\hline 1 & $\begin{array}{l}\text { Pan } \\
\text { el } \\
\text { Sur } \\
\text { ya }\end{array}$ & $\begin{array}{l}50 \\
W p\end{array}$ & $\begin{array}{l}\text { Rp. } \\
900 \\
.00 \\
0\end{array}$ & 1 & $\begin{array}{l}\mathrm{u} \\
\text { ni } \\
\mathrm{t}\end{array}$ & $\begin{array}{l}\text { Rp.900. } \\
000\end{array}$ \\
\hline 2 & $\begin{array}{l}\text { Bat } \\
\text { erai }\end{array}$ & $\begin{array}{l}45 \\
\mathrm{Ah}\end{array}$ & $\begin{array}{l}\text { Rp. } \\
800 \\
.00 \\
0\end{array}$ & 1 & $\begin{array}{l}\mathrm{u} \\
\mathrm{ni} \\
\mathrm{t}\end{array}$ & $\begin{array}{l}\text { Rp.800. } \\
000\end{array}$ \\
\hline 3 & $\begin{array}{l}\text { Kon } \\
\text { trol } \\
\text { er }\end{array}$ & $\begin{array}{l}10 \\
A \\
12 \\
V\end{array}$ & $\begin{array}{l}\mathrm{Rp} . \\
300 \\
.00 \\
0\end{array}$ & 1 & $\begin{array}{l}\mathrm{u} \\
\mathrm{ni} \\
\mathrm{t}\end{array}$ & $\begin{array}{l}\text { Rp.300. } \\
000\end{array}$ \\
\hline 4 & $\begin{array}{l}\mathrm{La} \\
\mathrm{mp} \\
\mathrm{u} \\
\mathrm{LE} \\
\mathrm{D}\end{array}$ & $\begin{array}{l}12 \\
W \\
12 \\
V\end{array}$ & $\begin{array}{l}\text { Rp. } \\
60 . \\
000\end{array}$ & 3 & $\begin{array}{l}\mathrm{u} \\
\text { ni } \\
\mathrm{t}\end{array}$ & $\begin{array}{l}\text { Rp. } 180 . \\
000\end{array}$ \\
\hline 5 & $\begin{array}{l}\text { Pen } \\
\text { gka } \\
\text { bela } \\
\text { n }\end{array}$ & - & $\begin{array}{l}\text { Rp. } \\
100 \\
.00 \\
0\end{array}$ & 1 & $\begin{array}{l}\mathrm{se} \\
\mathrm{t}\end{array}$ & $\begin{array}{l}\text { Rp. } 100 . \\
000\end{array}$ \\
\hline \multicolumn{6}{|c|}{ Total Jumlah } & $\begin{array}{l}\text { Rp. } 2.28 \\
0.000\end{array}$ \\
\hline
\end{tabular}

\section{Hasil dan Pembahasan}

\subsection{Data Pengujian Panel Surya 50 Wp}

Pengambilan data pengujian panel sel surya dilakukan mulai terbit matahari (pukul 06.00) samapai terbenamnya matahari (pukul 18.00). Data ini diambil untuk mengetahui berapa besar nilai tegangan rangkaian terbuka dari panel sel surya terhadap posisi sinar matahari. Tabel data pengamatan tegangan keluaran dari panel surya seperti dibawah ini :

Tabel 2. Data tegangan keluaran panel sel surya

\begin{tabular}{|c|c|c|c|c|}
\hline $\begin{array}{l}\mathbf{N} \\
\mathbf{0}\end{array}$ & Jam & $\begin{array}{c}\text { Tegang } \\
\text { an } \\
\text { (Volt) }\end{array}$ & $\begin{array}{c}\text { Aru } \\
\text { S } \\
(A)\end{array}$ & $\begin{array}{c}\text { Daya } \\
\text { Keluar } \\
\text { an } \\
\text { (W) }\end{array}$ \\
\hline
\end{tabular}




\begin{tabular}{|c|c|c|c|c|}
\hline 1 & $\begin{array}{c}06.0 \\
0\end{array}$ & 0,9 & 1 & 0,9 \\
\hline 2 & $\begin{array}{c}07.0 \\
0\end{array}$ & 16,7 & 1,2 & 20,04 \\
\hline 3 & $\begin{array}{c}08.0 \\
0\end{array}$ & 18,9 & 1,4 & 26,5 \\
\hline 4 & $\begin{array}{c}09.0 \\
0\end{array}$ & 19,6 & 2,6 & 51 \\
\hline 5 & $\begin{array}{c}10.0 \\
0\end{array}$ & 19,7 & 3,1 & 61,07 \\
\hline 6 & $\begin{array}{c}11.0 \\
0\end{array}$ & 20,8 & 3,1 & 64,5 \\
\hline 7 & $\begin{array}{c}12.0 \\
0\end{array}$ & 19,8 & 3,1 & 61,4 \\
\hline 8 & $\begin{array}{c}13.0 \\
0\end{array}$ & 20 & 3,1 & 62 \\
\hline 9 & $\begin{array}{c}14.0 \\
0\end{array}$ & 21,6 & 2,9 & 62,6 \\
\hline 10 & $\begin{array}{c}15.0 \\
0\end{array}$ & 19,5 & 2 & 39 \\
\hline 11 & $\begin{array}{c}16.0 \\
0\end{array}$ & 17,2 & 1,4 & 24,1 \\
\hline 12 & $\begin{array}{c}17.0 \\
0\end{array}$ & 16 & 1,2 & 19,2 \\
\hline 13 & $\begin{array}{c}18.0 \\
0\end{array}$ & 12 & 1,2 & 14,4 \\
\hline $\mathrm{Ra}$ & rata & 17,13 & 2,1 & 38,9 \\
\hline
\end{tabular}

Berdasarkan tabel 2 dapat dilihat bahwa tegangan tertinggi yang dihasilkan oleh panel sel surya adalah 21,6 volt yaitu pada saat pukul 14.00 sedangkan tegangan terendah adalah 0,9 volt pada saat pukul pukul 06.00 . Rata-rata daya keluaran yaitu 38,9 Watt.

\subsection{Data Perhitungan Pemakaian Baterai}

Pada perancangan PLTS ini menggunakan beban baterai $45 \mathrm{Ah} / 12$ $\mathrm{V}$ sehingga apabila pengisian penuh dapat menyimpan daya sebesar 540 Wh. Dengan perhitungan efektifitas baterai adalah $85 \%$ maka baterai dapat menyimpan daya sebesar 459 Wh. Dengan beban lampu LED yaitu 36 Watt maka pada perancangan ini baterai dapat digunakan selama 12,75 jam. Untuk pengisian baterai oleh panel surya $50 \mathrm{Wp}$ yaitu dengan ratarata daya keluaran sebesar 38,9 Wh maka pengisian baterai memerlukan waktu sekitar 13,8 jam.

\subsection{Data Perhitungan Nilai Ekonomis PLTS}

PLTS memerlukan perawatan teratur agar hasil keluaran dari perangkat tersebut dapat tercapai dengan maksimal. Perawatan PLTS lebih sering diperlukan pada baterai, jika penggunaan dan perawatan sesuai dengan aturan, rata-rata umur baterai dapat bertahan sampai 5 tahun, sedangkan biaya perawatan lainnya cenderung lebih murah. Usia pemakaian dari suatu komponen elektronik tergantung dari cara pemakaian. Makin sering dilakukan perawatan maka makin panjang pula usia komponen tersebut.

Dari tabel 1 dapat dilihat bahwa biaya awal teknologi PLTS yaitu sebesar Rp. 2.280.000,-. Di daerah 
pulau-pulau terpencil dimungkinkan dengan biaya sebesar dapat terpenuhi, karena PLTS merupakan sistem pembangkit listrik yang paling ekonomis dibandingkan pembangkit listrik lainnya. Keunggulan lain adalah PLTS tidak membutuhkan suplai bahan bakar dan jaringan distribusi listrik karena biasanya semakin terpencil sebuah daerah maka biaya suplai bahan bakar akan semakin tinggi dan pembangunan jaringan distribusi listrik akan semakin mahal. Namun apabila dihitung untuk pemakaian jangka panjang maka teknologi PLTS juga merupakan teknologi yang lebih murah dibandingkan dengan pemakaian genset yang biasanya dipakai di daerah hinterland. Di daerah hinterland kebanyakan menggunakan genset mandiri yang dipakai secara bersama-sama beberapa keluarga. Dimana masyarakat dipungut iuran sebesar antara Rp. 180.000 sampai Rp. 210.000 per bulan untuk pemakain listrik sebesar 2 Ampere selama 6 jam hidup.

Dari data diatas maka dapat dihitung nilai keuntungan menggunakan PLTS per bulannya. Apabila masa pakai peralatan PLTS ini adalah rata-rata 5 tahun (60 bulan) maka dengan pemakaian 2 Ampere perbulannya adalah Rp. 38.000 dengan pemakaian selama 12 jam hidup. Sehingga setiap bulanya masyarakat dapat menghemat biaya Rp. 142.000.

\section{Kesimpulan dan Saran}

\subsection{Kesimpulan}

1. Tegangan yang dihasilkan oleh panel sel surya $50 \mathrm{Wp}$ yang dipakai pada penelitian ini selama proses penyinaran sinar matahari selama
12 jam adalah 38,9 Watt. Pengisian baterai memerlukan waktu selama 13,8 jam, sedangkan discharge baterai untuk pemakaian ke beban lampu penerangan selama 12,75 jam.

2. Penghematan biaya pengeluaran listrik dengan mengunakan PLTS $50 \mathrm{Wp}$ dengan beban 36 Watt terhadap genset di daerah hinterland adalah sebesar Rp.142.000 per bulan.

\subsection{Saran}

Supaya lebih besar penghematan biaya yang diperoleh maka sebaiknya menggunakan kapasitas baterai yang sesuai dengan beban yang digunakan dengan toleransi yang lebih kecil.

\section{Daftar Pustaka}

- Ari Rahayuningyas, Seri Intan Kuala dan Ign. Fajar Apriyanto, 2014, Studi Perencanaan Sistem Pembangkit Listrik Tenaga Surya (PLTS) Skala Rumah Sederhana di Daerah Pedesaan Sebagai Pembangkit Listrik Alternatif Untuk Mendukung Program Ramah Lingkungan dan Energi Terbarukan, Prosiding Seminar Nasional Penelitian dan PKM Sains, Teknologi dan Kesehatan, Vol. 4, No. 1, Th 2014.

- Anwar Ilmar Ramadhan, Ery Diniardi dan Sony Hari Mukti, 2016, Analisis Desain Sistem Pembangkit Listrik Tenaga Surya Kapasitas 50 Wp, Jurnal TEKNIK, p-ISSN 0852-1697, e-ISSN 24609919

- Dafi Dzulfikar, Wisnu Broto, 2016, Optimalisasi Pemanfaatan Energi Listrik Tenaga Surya Skala Rumah Tangga, Prosiding 
Seminar Nasional Fisika, Vol. 5, Oktober 2016

- Jatmiko, Hasyim Asy'ari dan Mahir Purnama, 2011, Pemanfaatan Sel Surya dan Lampu LED Untuk Perumahan, Seminar Nasional Teknologi Informasi \& Komunikasi Terapan, ISBN 979-26-0255-0

- Kholid Akhmad, 2005, Pembangkit Listrik Tenaga Surya dan Penerapannya Untuk Daerah Terpencil, Jurnal Dinamika Rekayasa Vol.1 No.1 Hlm. 1-34, ISSN 1858-3075, Purwokerto, Agustus 2005

- Bansai, NK, et al, 1990, Renewable Energy Sources and Conversion Technology, Tata McGraw-Hill Publishing Co. Limited, New Delhi 